\title{
EMPIRICAL AND PETROPHYSICAL MODELS FOR SHALINESS ESTIMATION IN CLASTIC SEDIMENTARY ROCKS
}

\author{
Jorge Leonardo Martins ${ }^{1}$ and Thais Mallet de Castro
}

\begin{abstract}
Most of the sedimentary basins are composed of alternating layers of clastic lithotypes of mixed mineralogy, typically sandstones and shales. Having very small grains mean diameter, clay minerals can occur by contaminating void spaces, i.e., pores and pore connections, of oil-bearing reservoir rocks. It is thus necessary to establish a measure of the clay content in rocks - i.e., shaliness, which obstructs the tiny porous connections of reservoir rocks. In fact, shaliness represents a key petrophysical parameter, for instance, in the simulation process of oil and gas production. Being a petrophysical measure, shaliness can be better estimated from using the readings of the spontaneous potential and/or the natural gamma-ray logs. In practice, empirical models are used for estimating shaliness, although such models always lead to undesirable overestimations. Petrophysical models are alternatively proposed in the literature allowing more realistic estimates of shaliness. In this work, we present a new approach for the formulation of new petrophysical models for estimating shaliness using the binomial formula. By inserting the second-, the third- and the fourth-order binomial approximations for the Gaymard porosity formula into a simple shaliness-porosity relation, we obtain new petrophysical models for estimating shaliness which maintain the same properties of two models previously established in the literature. Experiments with real well-log data crossing the same turbiditic formation show more realistic - and very less uncertain - magnitudes for shaliness in an oil-producing arenitic reservoir, confirming the overestimated values of the empirical model taken as reference for the investigated lithology.
\end{abstract}

Keywords: geophysical well logs, shaliness estimation, empirical and petrophysical models, turbiditic reservoirs.

RESUMO. A maioria das bacias sedimentares é composta por camadas alternantes de litotipos clásticos de mineralogia mista, tipicamente arenitos e folhelhos. Possuindo diâmetro médio de grãos muito pequenos, os argilo-minerais podem contaminar os espaços vazios, i.e., os poros e as conexões entre poros das rochas acumuladoras de óleo e gás. Faz-se assim necessário o estabelecimento de uma medida do conteúdo de argila em rochas - i.e., da argilosidade, que obstrui as diminutas conexões porosas da rocha reservatório. De fato, a argilosidade representa um parâmetro petrofísico chave, por exemplo, no processo de simulação da produção de óleo e gás. Sendo uma medida petrofísica, a argilosidade pode ser melhor estimada a partir das leituras dos perfis de potencial espontâneo e/ou de raios gama naturais. Na prática, faz-se uso de modelos empíricos para estimar a argilosidade, embora tais modelos sempre conduzam a superestimativas indesejáveis. Modelos petrofísicos são alternativamente propostos na literatura, permitindo estimativas mais realistas de argilosidade. Neste trabalho, apresentamos uma nova abordagem para a formulação de modelos petrofísicos para estimativa de argilosidade usando a fórmula binomial. Ao inserirmos aproximações binomiais de segunda, terceira e quarta ordens para a fórmula da porosidade de Gaymard numa simples relação entre argilosidade e porosidade, obtemos novos modelos petrofísicos para estimativa de argilosidade que mantêm as mesmas propriedades de dois modelos estabelecidos na literatura. Experimentos com dados reais de perfis de poços que atravessam a mesma formação turbidítica mostram magnitudes mais realistas - e muito menos incertas - para a argilosidade em um reservatório arenítico produtor de óleo e gás, confirmando os valores superestimados do modelo empírico tomado como referência para a litologia investigada.

Palavras-chave: perfis geofísicos de poços, estimativa de argilosidade, modelos empíricos e petrofísicos, reservatórios turbidíticos.

\footnotetext{
${ }^{1}$ Observatório Nacional, Coordenação da Área de Geofísica, Ministério da Ciência, Tecnologia \& Inovação, Rua Gal. José Cristino, 77, São Cristóvão, 20921-400 Rio de Janeiro, RJ, Brazil. Phone: +55(21) 3504-9233; Fax: +55(21) 2580-7081 - E-mail: jImartins@on.br

2Universidade Federal Fluminense, Departamento de Geologia e Geofísica (LAGEMAR), Instituto de Geociências, Av. Gal. Milton Tavares de Souza, s/n, Boa Viagem, 24210-346 Niterói, RJ, Brazil. Phones: +55(21) 2629-5930/2629-5932 - E-mail: thais_mallet@hotmail.com
} 


\section{INTRODUCTION}

Sandstones and shales are the most frequently occurring lithotypes in clastic sedimentary basins, although thin layers of evaporites and carbonates can also be found in such sedimentary environments (Wyllie et al., 1958, Asquith \& Gibson, 1983). Because of the genetic complexity of clastic basins, most of the rocks found in such sedimentary environments present an equally complex mineralogical composition and grain size. It is well-known that some lithotypes always exhibit characteristic minerals, generally with a carbonate-type lithological cement. For instance: quartz is always found in sandstones as the main rock matrix mineral; in shales, clay minerals (e.g., kaolinite, illite, chlorite and smectite) occur as the predominant rock-forming minerals (Dewan, 1983; Ellis \& Singer, 2007). As clay minerals have a very small grain size - i.e., grains mean diameter in the order of $10^{-2} \mathrm{~mm}$ (Schön, 1996), shales can work as sealing rocks in the petroleum systems of clastic sedimentary basins. Worth mentioning is that shales, when classified as sealing rocks, act as barriers to the oil migration process from the source rocks, resulting in the accumulation of hydrocarbons in reservoir rocks (Asquith \& Gibson, 1983; Schön, 1996).

In practice, clay minerals are classified according to the way of occurrence in sedimentary lithologies (Asquith \& Gibson, 1983). There are three basic types of occurrence of clays in clastic sediments: laminar clays, structural clays, and dispersed clays. Laminar clays are generated from the organization of clay-forming laminations, while structural clays represent a singular distribution of clays which is found in the form of pellets (Dewan, 1983; Ellis \& Singer, 2007). Nevertheless, among the occurrences of clay minerals in clastic sediments, the dispersed clays are, by far, the most important type, arousing the interest of interpreters of geophysical well-log measurements. That is, dispersed clays impact on discriminating total porosity against effective porosity, explaining the relevance of such kind of occurrence of clay minerals. In defining total porosity, all void spaces - i.e., all the pores in the rocky matrix - are taken into account; instead, in the definition of effective porosity, only the connected pores are considered. Thus, among the three occurrences of the clay minerals, the dispersed clays arouse greater interest, once creating in porous rocks - e.g., oil-bearing sandstone reservoirs the obstruction of the small-diameter porous connections and the impediment of fluid flow between the tiny connections sometimes already obstructed by clays and/or hampered by oil viscosity. As a consequence, the clay occurrence associated with dispersed clays has a negative impact on the production of oil and gas (Dewan, 1983; Pennington, 2000). It is thus of crucial importance to establish a petrophysical measure able to evaluate the impact of dispersed clays on clastic rock quality in terms of production and oil-reserves estimation.

The concept of shaliness - sometimes also referred to as clay content - corresponds to the petrophysical measure which helps mitigate the uncertainties in the production of oil and gas. Shaliness is defined as the total volumetric percentage of dispersed clays present in clastic reservoirs, obstructing the porous connections which may be even already blocked by heavy oil. Using the empirical models available in the literature which take part in the majority of the well-log interpretation software packages, shaliness can be estimated from using the readings of the spontaneous potential log, SP, and/or the natural gamma-ray log, GR (Asquith \& Gibson, 1983; Dewan, 1983; Ellis \& Singer, 2007). The most used and simpler empirical models take the gammaray log measurements for estimating shaliness (Larionov, 1969; Stieber, 1970; Clavier et al., 1971; Brock, 1984), although radioactive minerals, supposedly found only in shales, can affect negatively shaliness estimation in oil-bearing sandstones (Ellis \& Singer, 2007). However, even without the presence of radioactive minerals in quartzose rocks, the empirical models used in the interpretation of geophysical logs overestimate shaliness, compromising the evaluation of effective porosity. Consequently, the uncertainties in the evaluation of the volume of recoverable oil from the reservoir grow enormously (Dewan, 1983; Schön, 1996; Pennington, 2000). In order to circumvent shaliness overestimation by using empirical models, Kamel \& Mabrouk (2003) and Mabrouk \& Kamel (2011) proposed petrophysical models which allow obtaining more realistic and less uncertain estimations. Instead of using gamma-ray readings, such petrophysical models incorporate the measurements of the three basic porosity logs into the derived formulas for shaliness estimation: the neutron porosity log, the sonic log, and the density $\log$ - hereafter referred to as $\phi_{\mathrm{N}}, \Delta \mathrm{t}$ and $\rho_{\mathrm{b}}$, respectively. Remarkably, such log measurements disregard gamma-ray amplitudes, being influenced only by the presence of clays contaminating the sediments. The results obtained in practice using such well-log measurements, in estimating shaliness more realistically, confirm the robustness of the petrophysical models proposed in Kamel \& Mabrouk (2003) and in Mabrouk \& Kamel (2011).

In this work, we apply the same assumptions as in Kamel \& Mabrouk (2003) and in Mabrouk \& Kamel (2011) in order to formulate new petrophysical models for estimating shaliness in clastic rocks. By relating shaliness to total and effective porosity in a very simple way, Kamel \& Mabrouk (2003) combined neutron porosity measurements with classical formulas for 
porosity. The insertion of such formulas into the mathematical formulation leads to a laborious algebraic handling, where the positive root of the so-obtained second-order equation provides a petrophysical model for shaliness. Considering the same shaliness-porosity relationship as in Kamel \& Mabrouk (2003), Mabrouk \& Kamel (2011) also combined neutron porosity readings with classical porosity formulas. The strategy, however, was to insert the effective sonic porosity relation into the mathematics, in order to simplify considerably the algebraic manipulations for deriving the shaliness model. As a result, the petrophysical models formulated by Kamel \& Mabrouk (2003) and by Mabrouk \& Kamel (2011) incorporate information from the three fundamental porosity logs - that is, $\phi_{\mathrm{N}}, \Delta \mathrm{t}$ and $\rho_{\mathrm{b}}$. As reported in Castro et al. (2014) and in Castro \& Martins (2016), comparison of current empirical models to such robust petrophysical models yields more realistic and less uncertain shaliness estimations. Nevertheless, the issue of interpreting gas-oil zones in the reservoir is absent in these previous formulations. As porosity estimates using the classical formulas reveal to be quite erroneous, estimating shaliness using the previously-obtained petrophysical models may indirectly provide a distinct behaviour in gas-oil zones. In this way, the proposal of this paper is to use binomial approximations (Boas, 1983) of the so-called Gaymard porosity formula (Gaymard \& Poupon, 1970) in order to deal with interpreting shaliness in possible gas-oil zones. Gaymard porosity formula applies to gas-oil zones (Dewan, 1983), also revealing suitability to incorporate neutron porosity readings into the shaliness model. Therefore, applying the second-, third- and fourth-order binomial approximations for Gaymard porosity formula to the mathematical procedures of Kamel \& Mabrouk (2003) and of Mabrouk \& Kamel (2011), we generate new petrophysical models for estimating shaliness which similarly hold information on the porosity logs $-\phi_{\mathrm{N}}, \Delta \mathrm{t}$ and $\rho_{\mathrm{b}}$. Experiments comparing these petrophysical models using actual well-log data crossing the same turbiditic lithology reveal equivalence in shaliness estimation. The results using previous models - i.e., those proposed by Kamel \& Mabrouk (2003) and by Mabrouk \& Kamel (2011) - exhibit slightly higher shaliness values in comparison with results using the models formulated on the basis of Gaymard porosity binomial approximations. However, as high-order terms of the binomial approximation of Gaymard porosity formula are considered in formulating the petrophysical model, shaliness estimates tend to be, as expected, virtually identical when compared to the previously proposed petrophysical models. The accuracy of the results is verified by statistical measures of the absolute error between the data taken as reference and the estimated data, confirming that the new petrophysical models provide more realistic and very less uncertain shaliness estimates than the empirical models.

\section{METHODOLOGY}

In the following, we present the mathematical formulation of three new petrophysical models for shaliness estimation. Firstly, we show the derivation of a model elaborated by Kamel \& Mabrouk (2003), and, secondly, the model proposed by Mabrouk \& Kamel (2011). In comparison to these previous models, the formulation of the additional new petrophysical models refers to a simpler mathematical approach using the binomial formula (Boas, 1983). The appropriate selection of a porosity formula is the central point in the mathematical derivations, resulting in petrophysical models for estimating shaliness which hold information on the three fundamental porosity logs, namely, the neutron porosity log, the density log, and the sonic log. In this way, we introduce basic formulas for estimating porosities using such geophysical well-log readings. It should be highlighted that only the neutron log represents a direct measure of porosity, being considered in practice as the direct measure of the total porosity of the rock (Dewan, 1983; Ellis \& Singer, 2007). On the other hand, density and sonic well-log readings provide indirect estimates of porosity from specific formulas. In order to provide ways for comparing shaliness estimation in the section of real data application below, the classical empirical models used in current interpretation workflows of geophysical well logs in clastic reservoirs are also briefly described.

\section{Petrophysical models for porosity}

The evaluation of porosity can be obtained from two ways: directly or indirectly. In the direct way, we use the neutron porosity well logging tool - which, as mentioned above, directly provides the neutron porosity measurements, $\phi_{\mathrm{N}}$. In the indirect way of evaluation of porosity, well-log readings of density, $\rho_{\mathrm{b}}$, and sonic slowness, $\Delta \mathrm{t}$, are used in simple petrophysical formulas to obtain estimates of total and effective porosity. Thus, density measurements are inserted into the following formulas in order to estimate total density porosity, $\phi_{\mathrm{t}} \equiv \phi_{\mathrm{t}, \mathrm{D}}$, and effective density porosity, $\phi_{\mathrm{e}} \equiv \phi_{\mathrm{e}, \mathrm{D}}$, respectively related as (Dewan, 1983; Schön, 1996):

$$
\phi_{\mathrm{t}, \mathrm{D}}=\frac{\rho_{\mathrm{ma}}-\rho_{\mathrm{b}}}{\rho_{\mathrm{ma}}-\rho_{\mathrm{f}}},
$$

and

$$
\phi_{\mathrm{e}, \mathrm{D}}=\phi_{\mathrm{t}, \mathrm{D}}-\mathrm{V}_{\text {clay }} \phi_{\mathrm{t}, \mathrm{D}, \text { clay }} .
$$

The term $\phi_{\mathrm{t}, \mathrm{D} \text {,clay }}$ is the apparent porosity at the "shale point". Using the readings of the density $\log , \rho_{\mathrm{b}}$, the apparent porosity 
is expressed as

$$
\phi_{\mathrm{t}, \mathrm{D}, \mathrm{clay}}=\frac{\rho_{\mathrm{ma}}-\rho_{\text {clay }}}{\rho_{\mathrm{ma}}-\rho_{\mathrm{f}}} .
$$

In the equations above, the parameters $\rho_{\text {clay }}, \rho_{\text {ma }}$ and $\rho_{\mathrm{f}}$ in practice are known beforehand, representing the density at the "shale point", the mean density value for the grain minerals in the rock matrix and the density for the fluid filling the pores, respectively. In general, the mud filtrate is the fluid in the zone of investigation (Dewan, 1983).

On the other hand, if the porosity estimation involves sonic slowness measurements, $\Delta \mathrm{t}$, we represent the total porosity and the effective porosity as $\phi_{\mathrm{t}} \equiv \phi_{\mathrm{t}, \mathrm{S}}$ and $\phi_{\mathrm{e}} \equiv \phi_{\mathrm{e}, \mathrm{S}}$, respectively. The relation for $\phi_{\mathrm{t}, \mathrm{S}}$ can be written as (Dewan, 1983; Schön, 1996)

$$
\phi_{\mathrm{t}, \mathrm{S}}=\frac{\Delta \mathrm{t}-\Delta \mathrm{t}_{\mathrm{ma}}}{\Delta \mathrm{t}_{\mathrm{f}}-\Delta \mathrm{t}_{\mathrm{ma}}}\left(\frac{100}{\Delta \mathrm{t}_{\text {clay }}}\right),
$$

in which, for the case of poorly-consolidated formations, the compaction factor has already been included (Dewan, 1983; Ellis \& Singer, 2007). The relation for $\phi_{\mathrm{e}, \mathrm{S}}$ can thus be expressed as:

$$
\phi_{\mathrm{e}, \mathrm{S}}=\phi_{\mathrm{t}, \mathrm{S}}-\mathrm{V}_{\text {clay }} \phi_{\mathrm{t}, \mathrm{S}, \text { clay }},
$$

where, the apparent porosity at the "shale point", $\phi_{\mathrm{t}, \mathrm{S}, \mathrm{clay}}$ is now written as:

$$
\phi_{\mathrm{t}, \mathrm{S}, \text { clay }}=\frac{\Delta \mathrm{t}_{\text {clay }}-\Delta \mathrm{t}_{\mathrm{ma}}}{\Delta \mathrm{t}_{\mathrm{f}}-\Delta \mathrm{t}_{\mathrm{ma}}} .
$$

The parameters $\Delta \mathrm{t}_{\text {clay }}, \Delta \mathrm{t}_{\text {ma }}$ and $\Delta \mathrm{t}_{\mathrm{f}}$, respectively, denote the sonic slowness at the "shale point", the mean value for the sonic slowness of the grain minerals forming the rock matrix and the value for the sonic slowness of the fluid filling the pores - i.e., the mud filtrate in the zone of investigation. Similarly, as in the case of using density measurements, $\Delta \mathrm{t}_{\text {clay }}, \Delta \mathrm{t}_{\text {ma }}$ and $\Delta \mathrm{t}_{\mathrm{f}}$ are also values selected beforehand. Note that Eqs. (1)-(6) can be easily derived assuming the conceptual model for a porous rock formed by parallel layers to which individual physical properties are assigned. For such conceptual model, the porous rock is formed by a solid portion (i.e., the rock matrix formed by the mineral grains, including clay minerals) and by a fluid portion which fully saturates the rock porous space. The so-called parallel-layer concept for a fluid-saturated porous rock can be found in Dewan (1983), Schön (1996) and Magalhães \& Martins (2012).

Nevertheless, a more robust relation for estimating porosity involves the combination of the neutron porosity, $\phi_{\mathrm{N}}$, and the total density porosity, $\phi_{\mathrm{t}, \mathrm{D}}$. In this case, $\phi_{\mathrm{t}} \equiv \phi_{\mathrm{t}, \mathrm{ND}}$, whose relationship is written as:

$$
\phi_{\mathrm{t}, \mathrm{ND}}=\delta \phi_{\mathrm{t}, \mathrm{D}}+(1-\delta) \phi_{\mathrm{N}}
$$

where $0.5 \leq \delta \leq 1.0$ (Dewan, 1983). In water zones, $\delta=0.5$, resulting in (Asquith \& Gibson, 1983):

$$
\phi_{\mathrm{t}, \mathrm{ND}}=\frac{\phi_{\mathrm{N}}+\phi_{\mathrm{t}, \mathrm{D}}}{2} .
$$

However, in gas zones, the use of Gaymard porosity formula (Gaymard \& Poupon, 1970) is more appropriate for porosity estimation,

$$
\phi_{\mathrm{t}, \mathrm{ND}}^{2}=\frac{\phi_{\mathrm{N}}^{2}+\phi_{\mathrm{t}, \mathrm{D}}^{2}}{2} .
$$

Note that it is possible to consider the formula for effective porosity, $\phi_{\mathrm{e}, \mathrm{ND}}$, in Eqs. (7), (8) and (9) by substituting the terms involved in the corresponding relations.

\section{Empirical models for shaliness}

By using the natural gamma-ray log measurements to estimate shaliness, the calculation of the gamma-ray index, GRI, represents the common point among the classical empirical models. This mandatory input parameter is related as

$$
\mathrm{GRI}=\frac{\mathrm{GR}_{\log }-\mathrm{GR}_{\log , \min }}{\mathrm{GR}_{\log , \max }-\mathrm{GR}_{\log , \min }},
$$

in which $\mathrm{GR}_{\log }$ denotes the reading of the gamma-ray log at a selected depth. For the same sedimentary interval investigated, $\mathrm{GR}_{\log \text {,max }}$ and $\mathrm{GR}_{\log \text {,min }}$ denote the maximum and minimum readings, respectively (Dewan, 1983).

The study of Larionov (1969) proposes the following empirical relation for estimating shaliness $\mathrm{V}_{\text {clay }}$ in Tertiary rocks (i.e., young sediments):

$$
\mathrm{V}_{\text {clay }}=0.083\left[2^{3.7 \times \mathrm{GRI}}-1\right] \text {, }
$$

while, for older rocks, Larionov (1969) applies

$$
\mathrm{V}_{\text {clay }}=0.33\left[2^{2.0 \times \mathrm{GRI}}-1\right] \text {. }
$$

Brock (1984) proposes a relation for $\mathrm{V}_{\text {clay }}$ in rocks from the Oligocene-Miocene which has a mathematical structure similar to Larionov (1969) equations, namely:

$$
\mathrm{V}_{\text {clay }}=0.21\left[2^{2.9 \times \mathrm{GRI}}-1\right] \text {. }
$$

In turn, also considering the rock age, Stieber (1970) derived that

$$
\mathrm{V}_{\text {clay }}=\frac{\mathrm{GRI}}{\mathrm{A}-(\mathrm{A}-1) \times \mathrm{GRI}},
$$

in which the parameter $\mathrm{A}$ assumes the following values: $\mathrm{A}=3$, $\mathrm{A}=2$ and $\mathrm{A}=0.15$ for Tertiary rocks, older rocks and Cretaceous rocks, respectively. 
At last but not least, it follows the empirical model proposed in Clavier et al. (1971) for estimating $\mathrm{V}_{\text {clay }}$ :

$$
\mathrm{V}_{\text {clay }}=1.70-\sqrt{3.38-[\mathrm{GRI}+0.7]^{2}} .
$$

Because the regression coefficients of each empirical model are associated with specific rocks, the validity of the empirical models above is always questionable. In other words, the sedimentary characteristics of the rocks used to construct the empirical models are always distinct from the rocks under study. This property can be observed in Figure 1, which displays the relationship of shaliness with the increase of GRI according to the empirical models in Eqs. (11)-(15). Except for the Brock (1984) model in Eq. (13) and the Stieber (1970) model (A=0.15) in Eq. (14), the empirical models for shaliness present similar trends.

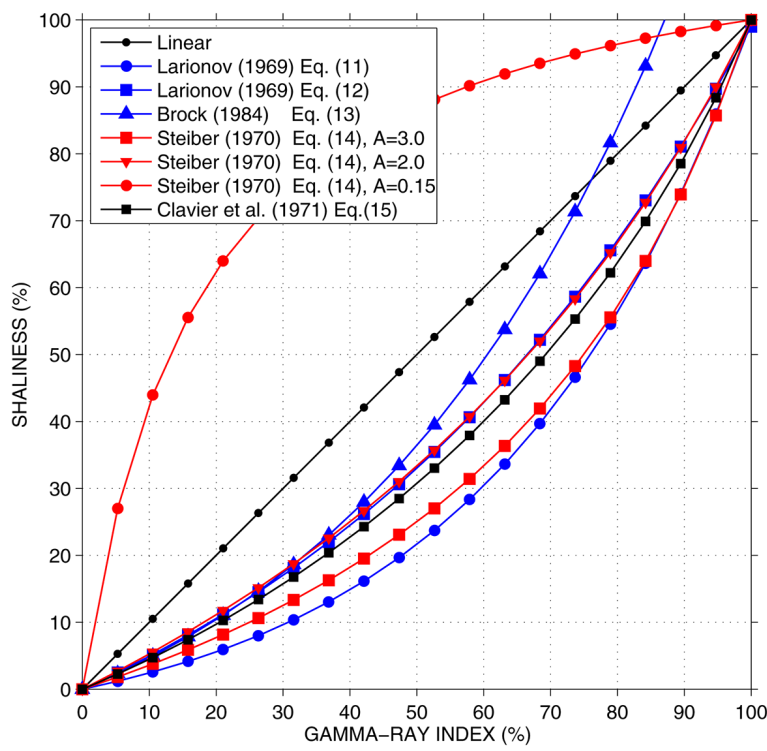

Figure 1 - Display showing the trends of the empirical models for shaliness related in Eqs. (11-15). The linear curve represents the GRI value itself - see Eq. (10). As noticed, most of the empirical models respond with similar behaviour for shaliness variation. Only the Brock (1984) model in Eq. (13) and the Stieber (1970) model $(\mathrm{A}=0.15)$ in Eq. (14) display very distinct trends.

\section{Petrophysical models for shaliness}

The mathematical formulation for the petrophysical models for shaliness presented below are based on the relationship between the total porosity, $\phi_{\mathrm{t}}$, the effective porosity, $\phi_{\mathrm{e}}$, and the apparent porosity at the "shale point", $\phi_{\text {clay }}$, namely:

$$
\phi_{\mathrm{e}}=\phi_{\mathrm{t}}-\mathrm{V}_{\text {clay }} \phi_{\text {clay }},
$$

which may be rewritten as

$$
\mathrm{V}_{\text {clay }}=\frac{\phi_{\mathrm{t}}-\phi_{\mathrm{e}}}{\phi_{\text {clay }}}
$$

As proposed in Kamel \& Mabrouk (2003) and in Mabrouk \& Kamel (2011), in very shaly clastic sedimentary formations, we are allowed to approximate $\mathrm{V}_{\text {clay }} \approx 100 \%$ so that $\phi_{\mathrm{e}} \approx 0$. In this way $\phi_{\mathrm{t}} \approx \phi_{\text {clay }}$, and Eq. (17) evolves to:

$$
\mathrm{V}_{\text {clay }}=1-\frac{\phi_{\mathrm{e}}}{\phi_{\mathrm{t}}} .
$$

The preceding equation is the building block for the formulation of petrophysical models for shaliness. As we shall see in the following, the relation for the total porosity, $\phi_{\mathrm{t}}$, can be substituted using $\phi_{\mathrm{t}} \equiv \phi_{\mathrm{t}, \mathrm{ND}}$ [see Eqs. (7), (8) and (9)]; as for the effective porosity $\phi_{\mathrm{e}}$, we can approximate either $\phi_{\mathrm{e}} \equiv \phi_{\mathrm{e}, \mathrm{D}}$ [see Eq. (2)] or $\phi_{\mathrm{e}} \equiv \phi_{\mathrm{e}, \mathrm{S}}$ [see Eq. (5)].

\section{(1) The Kamel \& Mabrouk (2003) model}

The petrophysical model for estimating $\mathrm{V}_{\text {clay }}$ proposed in Kamel \& Mabrouk (2003) uses Eq. (8) assuming $\phi_{\mathrm{t}, \mathrm{D}} \equiv \phi_{\mathrm{e}, \mathrm{D}}$. In the same way, the mathematical formulation considers $\phi_{\mathrm{e}} \equiv \phi_{\mathrm{e}, \mathrm{S}}$ and $\phi_{\mathrm{t}} \equiv \phi_{\mathrm{t}, \mathrm{ND}}$ in Eq. (18), leading to

$$
\mathrm{V}_{\text {clay }}=\frac{\phi_{\mathrm{N}}+\phi_{\mathrm{e}, \mathrm{D}}-2 \phi_{\mathrm{e}, \mathrm{S}}}{\phi_{\mathrm{N}}+\phi_{\mathrm{e}, \mathrm{D}}}
$$

Notice that Eq. (19) holds information on the three fundamental porosity logs. Thus, inserting Eqs. (2) and (5) for $\phi_{\mathrm{e}, \mathrm{D}}$ and $\phi_{\mathrm{e}, \mathrm{S}}$, respectively, into the preceding relation, we can write (Kamel \& Mabrouk, 2003; Castro et al., 2014; Castro \& Martins, 2016):

$$
\mathcal{A}_{1} \mathrm{~V}_{\text {clay }}^{2}+\mathcal{B}_{1} \mathrm{~V}_{\text {clay }}+\mathcal{C}_{1}=0
$$

in which $\mathcal{A}_{1}=\phi_{\mathrm{t}, \mathrm{D}, \text { clay }}, \mathcal{B}_{1}=-\left(\phi_{\mathrm{N}}+\phi_{\mathrm{t}, \mathrm{D}}+\phi_{\mathrm{t}, \mathrm{D}, \text { clay }}-\right.$ $\left.2 \phi_{\mathrm{t}, \mathrm{S}, \text { clay }}\right)$, and $\mathcal{C}_{1}=\phi_{\mathrm{N}}+\phi_{\mathrm{t}, \mathrm{D}}-2 \phi_{\mathrm{t}, \mathrm{S}}$. As the range of variation for shaliness is $0 \leq \mathrm{V}_{\text {clay }} \leq 1$, we take the positive square root of Eq. (20) for obtaining the petrophysical model for $\mathrm{V}_{\text {clay }}$ according to Kamel \& Mabrouk (2003):

$$
\mathrm{V}_{\text {clay }}=\frac{-\mathcal{B}_{1}+\sqrt{\mathcal{B}_{1}^{2}-4 \mathcal{A}_{1} \mathcal{C}_{1}}}{2 \mathcal{A}_{1}}
$$

The constants $\mathcal{A}_{1}, \mathcal{B}_{1}$ and $\mathcal{C}_{1}$ incorporates the relations for $\phi_{\mathrm{t}, \mathrm{D}}, \phi_{\mathrm{t}, \mathrm{D}, \text { clay }}, \phi_{\mathrm{t}, \mathrm{S}}$ and $\phi_{\mathrm{t}, \mathrm{S}, \text { clay }}$ provided in Eqs. (1), (3), (4) and (6), respectively.

\section{(2) The Mabrouk \& Kamel (2011) model}

The model for shaliness estimation proposed in Mabrouk \& Kamel (2011) shows a more simplified mathematical formulation, inserting $\phi_{t, D}$ as in Eq. (1) into Eq. (8). Further, it also considers 
$\phi_{\mathrm{t}} \equiv \phi_{\mathrm{t}, \mathrm{ND}}$ and $\phi_{\mathrm{e}} \equiv \phi_{\mathrm{e}, \mathrm{S}}$ in Eq. (18). After these substitutions, we can write:

$$
\mathrm{V}_{\text {clay }}=\frac{\phi_{\mathrm{N}}+\phi_{\mathrm{t}, \mathrm{D}}-2 \phi_{\mathrm{e}, \mathrm{S}}}{\phi_{\mathrm{N}}+\phi_{\mathrm{t}, \mathrm{D}}},
$$

where it can be seen that the three porosity logs also contribute to the construction of this proposed petrophysical model for shaliness. The algebraic manipulations which follow after the correspondent substitutions for $\phi_{\mathrm{t}, \mathrm{D}}$ and $\phi_{\mathrm{e}, \mathrm{S}}$, provide a yet more simplified petrophysical model for shaliness (Mabrouk \& Kamel, 2011), that is:

$\mathrm{V}_{\text {clay }}=\frac{\phi_{\mathrm{N}}+\mathcal{A}_{2}\left(\rho_{\mathrm{b}}-\rho_{\mathrm{ma}}\right)-\mathcal{B}_{2}\left(\Delta \mathrm{t}-\Delta \mathrm{t}_{\mathrm{ma}}\right)}{\phi_{\mathrm{N}}+\mathcal{A}_{2}\left(\rho_{\mathrm{b}}-\rho_{\mathrm{ma}}\right)-2 \mathcal{C}_{2}}$,

in which the constants $\mathcal{A}_{2}, \mathcal{B}_{2}$ and $\mathcal{C}_{2}$ are related as:

$$
\mathcal{A}_{2}=\frac{1}{\left(\rho_{\mathrm{f}}-\rho_{\mathrm{ma}}\right)}, \quad \mathcal{B}_{2}=\frac{200}{\left[\Delta \mathrm{t}_{\text {clay }}\left(\Delta \mathrm{t}_{\mathrm{f}}-\Delta \mathrm{t}_{\mathrm{ma}}\right)\right]},
$$

and $\mathcal{C}_{2}=\phi_{\mathrm{t}, \mathrm{S}, \text { clay }}$.

\section{(3) The new petrophysical models}

The investigations of Castro et al. (2014) and Castro \& Martins (2016) shows that the petrophysical models above provide more realistic and accurate shaliness estimations in clastic reservoirs, even if highly radioactive shales - or another radioactive materials, other than shales - are present in the reservoir formation. However, a relevant issue to take into account is the occurrence of light hydrocarbons in the reservoir formation. In this instance, we apply Gaymard porosity formula as the basis for formulations of, even further simpler, new petrophysical models for shaliness. To this end, we then rewrite Eq. (9) as follows:

$$
\phi_{\mathrm{t}, \mathrm{ND}}=\sqrt{\frac{1}{2}}\left(\phi_{\mathrm{N}}^{2}+\phi_{\mathrm{t}, \mathrm{D}}^{2}\right)^{1 / 2} .
$$

In order to avoid introducing nonlinear terms along the algebraic handling that follows in the formulation of the new petrophysical models, we approximate Eq. (24) using the binomial formula (Boas, 1983) up to the fourth order. Appendix A shows details of such approximation.

Following Mabrouk \& Kamel (2011), we then insert $\phi_{\mathrm{t}} \equiv$ $\phi_{\mathrm{t}, \mathrm{ND}}$ and $\phi_{\mathrm{e}} \equiv \phi_{\mathrm{e}, \mathrm{S}}$ into Eq. (18). For $\phi_{\mathrm{t}, \mathrm{ND}}$, we assume the second-order approximation expressed in Eq. (A2); for $\phi_{\mathrm{e}, \mathrm{S}}$, we use Eq. (5). The subsequent algebraic handling yields the following simpler new petrophysical model for shaliness:

$$
\mathrm{V}_{\text {clay }}=\frac{\sqrt{\frac{1}{2}}\left(\phi_{\mathrm{N}}+\phi_{\mathrm{t}, \mathrm{D}}^{2} / 2 \phi_{\mathrm{N}}\right)-\mathcal{A}_{3}}{\sqrt{\frac{1}{2}}\left(\phi_{\mathrm{N}}+\phi_{\mathrm{t}, \mathrm{D}}^{2} / 2 \phi_{\mathrm{N}}\right)-\mathcal{B}_{3}},
$$

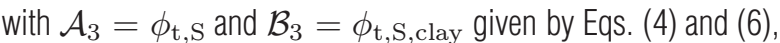
respectively. Similarly, as the petrophysical models due to Kamel \& Mabrouk (2003) and to Mabrouk \& Kamel (2011), the model in Eq. (25) also holds information on the three fundamental porosity logs. Note that the third- and fourth-order binomial approximations for Eq. (24) can provide more accurate models than the relation given in Eq. (25). In this way, taking the third-order binomial approximation in Eq. (A3), shaliness can also be estimated using

$$
\mathrm{V}_{\text {clay }}=\frac{\sqrt{\frac{1}{2}}\left(\phi_{\mathrm{N}}+\frac{\phi_{\mathrm{t}, \mathrm{D}}^{2}}{2 \phi_{\mathrm{N}}}-\frac{\phi_{\mathrm{t}, \mathrm{D}}^{4}}{8 \phi_{\mathrm{N}}^{3}}\right)-\mathcal{A}_{3}}{\sqrt{\frac{1}{2}}\left(\phi_{\mathrm{N}}+\frac{\phi_{\mathrm{t}, \mathrm{D}}^{2}}{2 \phi_{\mathrm{N}}}-\frac{\phi_{\mathrm{t}, \mathrm{D}}^{4}}{8 \phi_{\mathrm{N}}^{3}}\right)-\mathcal{B}_{3}},
$$

or, assuming the fourth-order binomial approximation in Eq. (A4),

$$
\mathrm{V}_{\text {clay }}=\frac{\sqrt{\frac{1}{2}}\left(\phi_{\mathrm{N}}+\frac{\phi_{\mathrm{t}, \mathrm{D}}^{2}}{2 \phi_{\mathrm{N}}}-\frac{\phi_{\mathrm{t}, \mathrm{D}}^{4}}{8 \phi_{\mathrm{N}}^{3}}+\frac{\phi_{\mathrm{t}, \mathrm{D}}^{6}}{16 \phi_{\mathrm{N}}^{5}}\right)-\mathcal{A}_{3}}{\sqrt{\frac{1}{2}}\left(\phi_{\mathrm{N}}+\frac{\phi_{\mathrm{t}, \mathrm{D}}^{2}}{2 \phi_{\mathrm{N}}}-\frac{\phi_{\mathrm{t}, \mathrm{D}}^{4}}{8 \phi_{\mathrm{N}}^{3}}+\frac{\phi_{\mathrm{t}, \mathrm{D}}^{6}}{16 \phi_{\mathrm{N}}^{5}}\right)-\mathcal{B}_{3}},
$$

The experiments in the following section confirm the accuracy obtained with the new petrophysical model for shaliness derived using the fourth-order binomial approximation for Gaymard porosity formula in Eq. (24).

\section{RESULTS}

This section shows the experiments with the above-described petrophysical models for shaliness. For implementing the experiments, we selected geophysical logs from two vertical wells, nearly $2 \mathrm{~km}$ apart, drilled through a turbiditic, Albian-aged, oilproducing shaly-sandstone intervals in Campos basin, offshore Brazil. We follow three steps to produce the results below:

(1) description of the geology and the geophysical well-log data set;

(2) comparison of porosity logs; and

(3) comparison of shaliness logs, $V_{\text {clay }}$.

In steps (2) and (3), the selection of a reference log was fundamental for calculating the statistical measures which take part in the uncertainty analyses shown in Tables 1 and 2. Note that the statistical measures are calculated over the absolute error between the reference log and an estimated log. In this way, Gaymard porosity in Eq. (24) provides the reference porosity log in step (2); Larionov (1969) empirical model for young sediments given in Eq. (11) is assumed as the reference shaliness log in step (3). Moreover, the needed parameters for calculating the total sonic 
Table 1 - Statistics for the uncertainty analysis of porosity comparisons using well logs from WELL-A and WELL-B. Statistical measures calculated over the absolute error in porosity, assuming the Gaymard porosity in Eq. (24) as the reference. In this way, $\mathrm{e}_{\min }, \mathrm{e}_{\text {mean }}, \mathrm{e}_{\max }, \sigma_{\mathrm{e}}$ and $\sigma_{\mathrm{e}}^{2}$ denote the minimum absolute error, the mean absolute error, the maximum absolute error, the standard deviation of the absolute error and the variance of the absolute error, respectively. Porosity, $\phi_{\mathrm{t}, \mathrm{ND}}$, in percentage.

\begin{tabular}{|c|c|c|c|}
\hline \multicolumn{4}{|c|}{ WELL-A } \\
\hline STATISTICS & $\left\|\phi_{\mathrm{t}, \mathrm{ND}}^{\text {Eq. }(24)}-\phi_{\mathrm{t}, \mathrm{ND}}^{\text {Eq. }(\mathrm{A} 2)}\right\|$ & \|\|$_{\mathrm{t}, \mathrm{ND}}^{\text {Eq. }}(24)-\phi_{\mathrm{t}, \mathrm{ND}}^{\text {Eq. (A3) }} \|$ & $\left\|\phi_{\mathrm{t}, \mathrm{ND}}^{\text {Eq. }(24)}-\phi_{\mathrm{t}, \mathrm{ND}}^{\text {Eq. }(\mathrm{A} 4)}\right\|$ \\
\hline $\mathrm{e}_{\min }$ & 0.00 & 0.00 & 0.00 \\
\hline $\mathrm{e}_{\text {mean }}$ & 1.59 & 1.12 & 1.16 \\
\hline $\mathrm{e}_{\max }$ & 5.90 & 6.34 & 11.85 \\
\hline$\sigma_{\mathrm{e}}$ & 1.46 & 1.39 & 1.83 \\
\hline$\sigma_{\mathrm{e}}^{2}$ & 2.13 & 1.93 & 3.36 \\
\hline \multicolumn{4}{|c|}{ WELL-B } \\
\hline STATISTICS & $\left\|\phi_{\mathrm{t}, \mathrm{ND}}^{\text {Eq. }(24)}-\phi_{\mathrm{t}, \mathrm{ND}}^{\text {Eq. (A2) }}\right\|$ & $\left\|\phi_{t, \mathrm{ND}}^{\text {Eq. (24) }}-\phi_{\mathrm{t}, \mathrm{ND}}^{\text {Eq. (A3) }}\right\|$ & $\left\|\phi_{\mathrm{t}, \mathrm{ND}}^{\text {Eq. }(24)}-\phi_{\mathrm{t}, \mathrm{ND}}^{\text {Eq. (A4) }}\right\|$ \\
\hline $\mathrm{e}_{\min }$ & 0.00 & 0.00 & 0.00 \\
\hline $\mathrm{e}_{\text {mean }}$ & 1.12 & 0.62 & 0.47 \\
\hline $\mathrm{e}_{\max }$ & 4.14 & 4.05 & 5.32 \\
\hline$\sigma_{\mathrm{e}}$ & 1.04 & 0.69 & 0.64 \\
\hline$\sigma_{\mathrm{e}}^{2}$ & 1.07 & 0.48 & 0.41 \\
\hline
\end{tabular}

Table 2 - Statistics for the uncertainty analysis of comparing shaliness estimations using well logs from WELL-A and WELL-B. Statistical measures calculated over the absolute error in shaliness, with Larionov (1969) empirical model for young sediments in Eq. (11) as the reference. In this way, $\mathrm{e}_{\min }, \mathrm{e}_{\operatorname{mean}}, \mathrm{e}_{\max }, \sigma_{\mathrm{e}}$ and $\sigma_{\mathrm{e}}^{2}$ represent the minimum absolute error, the mean absolute error, the maximum absolute error, the standard deviation of the absolute error and the variance of the absolute error, respectively. Shaliness, $\mathrm{V}_{\text {clay }}$, in percentage.

\begin{tabular}{|c|c|c|c|c|}
\hline \multicolumn{5}{|c|}{ WELL-A } \\
\hline STATISTICS & $\left\|\mathrm{V}_{\text {clay }}^{\text {Eq. (11) }}-\mathrm{V}_{\text {clay }}^{\text {Eq. (21) }}\right\|$ & $\left\|\mathrm{V}_{\text {clay }}^{\text {Eq. (11) }}-\mathrm{V}_{\text {clay }}^{\text {Eq. (23) }}\right\|$ & $\left\|\mathrm{V}_{\text {clay }}^{\text {Eq. }(11)}-\mathrm{V}_{\text {clay }}^{\text {Eq. (25) }}\right\|$ & $\left\|\mathrm{V}_{\text {clay }}^{\text {Eq. }(11)}-\mathrm{V}_{\text {clay }}^{\text {Eq. (27) }}\right\|$ \\
\hline $\mathrm{e}_{\min }$ & 0.00 & 0.00 & 0.00 & 0.00 \\
\hline $\mathrm{e}_{\text {mean }}$ & 11.81 & 11.87 & 12.82 & 12.21 \\
\hline $\mathrm{e}_{\max }$ & 67.67 & 70.70 & 74.09 & 73.71 \\
\hline$\sigma_{\mathrm{e}}$ & 9.92 & 9.77 & 9.65 & 9.51 \\
\hline$\sigma_{\mathrm{e}}^{2}$ & 98.48 & 95.57 & 93.18 & 90.47 \\
\hline \multicolumn{5}{|c|}{ WELL-B } \\
\hline STATISTICS & $\left\|\mathrm{V}_{\text {clay }}^{\text {Eq. (11) }}-\mathrm{V}_{\text {clay }}^{\text {Eq. (21) }}\right\|$ & $\left\|\mathrm{V}_{\text {clay }}^{\text {Eq. (11) }}-\mathrm{V}_{\text {clay }}^{\text {Eq. (23) }}\right\|$ & $\left\|\mathrm{V}_{\text {clay }}^{\text {Eq. (11) }}-\mathrm{V}_{\text {clay }}^{\text {Eq. (25) }}\right\|$ & $\left\|\mathrm{V}_{\text {clay }}^{\text {Eq. (11) }}-\mathrm{V}_{\text {clay }}^{\text {Eq. (27) }}\right\|$ \\
\hline $\mathrm{e}_{\min }$ & 0.00 & 0.00 & 0.00 & 0.00 \\
\hline $\mathrm{e}_{\text {mean }}$ & 25.17 & 25.67 & 27.31 & 26.80 \\
\hline $\mathrm{e}_{\max }$ & 95.55 & 95.87 & 98.01 & 97.51 \\
\hline$\sigma_{\mathrm{e}}$ & 15.94 & 16.02 & 16.38 & 16.28 \\
\hline$\sigma_{\mathrm{e}}^{2}$ & 253.93 & 256.70 & 268.24 & 264.97 \\
\hline
\end{tabular}


porosity $\log , \phi_{\mathrm{t}, \mathrm{S}}$, the total density porosity $\log , \phi_{\mathrm{t}, \mathrm{D}}$, the Gaymard porosity $\log , \phi_{\mathrm{t}, \mathrm{ND}}$, and the shaliness $\log , \mathrm{V}_{\text {clay }}$, are set as: $\Delta \mathrm{t}_{\mathrm{ma}}=55.50 \mu \mathrm{s} / \mathrm{ft}, \Delta \mathrm{t}_{\mathrm{f}}=189 \mu \mathrm{s} / \mathrm{ft}, \Delta \mathrm{t}_{\text {clay }}=$ $115 \mu \mathrm{s} / \mathrm{ft}, \rho_{\mathrm{ma}}=2.65 \mathrm{~g} / \mathrm{cm}^{3}$ and $\rho_{\mathrm{f}}=1.10 \mathrm{~g} / \mathrm{cm}^{3}$. The interpretation of well logs in the studied area provided the parameter $\Delta t_{\text {clay }}$ that represents the sonic slowness for a dominant shale in the sedimentary interval under analysis. For this dominant shale, $\rho_{\text {clay }}=2.54 \mathrm{~g} / \mathrm{cm}^{3}$.

\section{WELL-A}

WELL-A is located in the central part of a turbiditic reservoir, exhibiting a complex distribution of facies. In Figure 2, the panel in the middle shows the lithology column, depicting oilproducing sandstone intervals intercalated by thin layers of calcareous shales, calcilutites, siltites and shales. The mineralogical analysis implemented in Magalhães \& Martins (2012) reveals the presence of high percentage of feldspar in the sandstone intervals, confirming the arcosean nature of the reservoir reported in several papers - see for instance Bacoccoli et al. (1980) and Tigre \& Lucchesi (1986). The geophysical anomalies observed in the log curves can be easily correlated with the facies exhibited in the lithology column. In Figure 2a, the high gamma-ray intensities shown in the gamma-ray well log are consequence of the abundance of feldspar in the sediments; in Figure 2b, the electrical deep resistivity anomalies are associated to oil-bearing sandstone intervals; and, in Figure 2c, the low-density anomalies in the density log correlate with producing zones. As porosity measurements play a key role in the estimation of shaliness using the petrophysical models presented above, we then plotted in Figure $2 \mathrm{~d}$ the neutron porosity $\log , \phi_{\mathrm{N}}$, together with the further total porosity logs, i.e., the total density porosity $\log , \phi_{\mathrm{t}, \mathrm{D}}$, the total sonic $\log , \phi_{\mathrm{t}, \mathrm{S}}$ and the Gaymard porosity log, $\phi_{\mathrm{t}, \mathrm{ND}}$ according to Eqs. (1), (4) and (24), respectively. Note that the measurements of sonic slowness in Figure 2a were incorporated into Eq. (4), generating the $\phi_{\mathrm{t}, \mathrm{S}} \log$. As a result, Figure $2 \mathrm{~d}$ shows that the entire total porosity curves basically display the same trend, with Gaymard porosity running between the neutron porosity log and the total density porosity log, as predicted by Eq. (24).

However, concerning porosity calculations, a better comparison is displayed in Figure 3. The neutron porosity $\log , \phi_{\mathrm{N}}$, is plotted as a reference log, while the Gaymard porosity log - calculated as in Eq. (24) - is compared to the second-, third- and fourth-order binomial approximations expressed in Eqs. (A2), (A3) and Eq. (A4), respectively. These approximations are displayed in Figures 3a, 3b and 3c, revealing a critical fitting to Gaymard porosity in the sandstone intervals. Remarkably, the binomial approximations for Gaymard porosity nearly generate the same results, with the third-order binomial approximation providing a slightly better fitting. The uncertainty analysis is shown in Table 1 for the Gaymard porosity and the corresponding approximations using the data set from WELL-A give support for such observations.

The estimates of shaliness resulting from the applications of the petrophysical models are plotted in Figure 4. The model presented in Kamel \& Mabrouk (2003), in Eq. (21), and the model proposed in Mabrouk \& Kamel (2011), in Eq. (23), are respectively displayed in Figures 4a and 4b. In turn, the new petrophysical models derived by using the second- and fourth-order binomial approximation of Gaymard porosity - Eqs. (25) and (27), are respectively plotted in Figures $4 \mathrm{c}$ and $4 \mathrm{~d}$. The analysis of Figure 4 shows that the petrophysical models yield very equivalent results, providing shaliness estimates always smaller than Larionov (1969) empirical model. As it can be observed in Figure 4 , shaliness decreases practically along the entire sedimentary interval, mainly in the facies showing high gamma-ray anomalies. Unlike Larionov (1969) empirical model, the petrophysical models predict shaliness without bringing such high anomalies into the estimation of shaliness. Using the data set from WELL-A, the equivalence of the petrophysical models in predicting shaliness is confirmed by the uncertainty analysis shown in Table 2 .

\section{WELL-B}

WELL-B is located near the border of the turbiditic reservoir, thus presenting less inner geological complexity. The lithology column in the middle panel of Figure 5 depicts the facies at the borehole surroundings. Facies interpretation in this well reveals two main oil-producing sandstone intervals, with shales and carbonates occurring as sealing layers. The geophysical anomalies in the welllog measurements easily correlate with the facies interpreted in the lithology column. Because of the arcosean nature of the reservoir, high gamma-ray amplitudes occur in the gamma-ray log see Figure $5 a$ - along the sandstone intervals. The oil-producing zones can be correlated clearly with the significantly high anomalies exhibited by the electrical resistivity log in Figure $5 b$. The density log in Figure $5 \mathrm{c}$ also reflects the lithology column at the surroundings of WELL-B, enabling the correlation of the sandstone intervals with low-density anomalies and sealing facies with high-density anomalies. In order to calculate the total porosity logs - i.e, the total density porosity $\log , \phi_{\mathrm{t}, \mathrm{D}}$, the total sonic porosity $\log , \phi_{\mathrm{t}, \mathrm{S}}$, and the Gaymard porosity $\log , \phi_{\mathrm{t}, \mathrm{ND}}$, the 


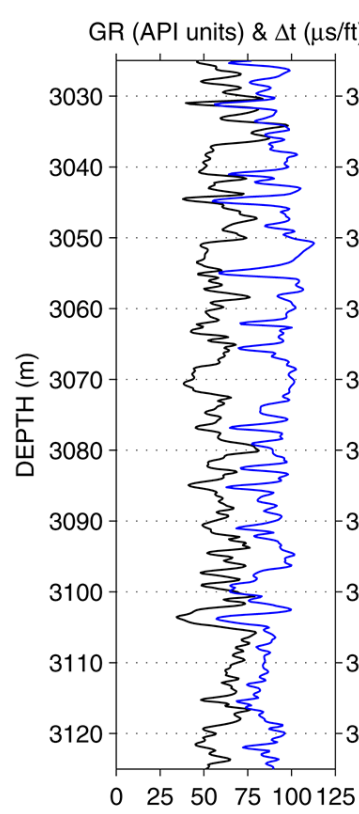

(a)

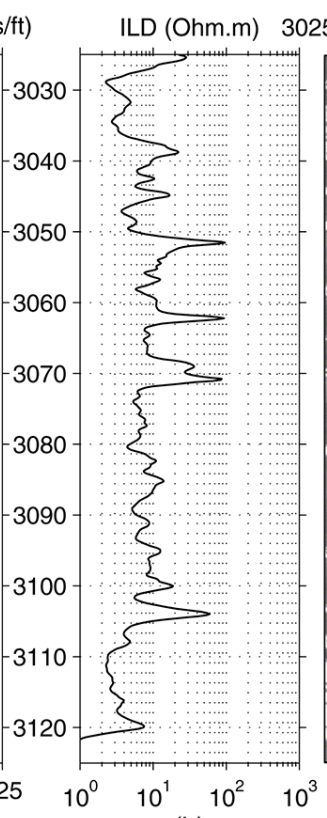

(b)

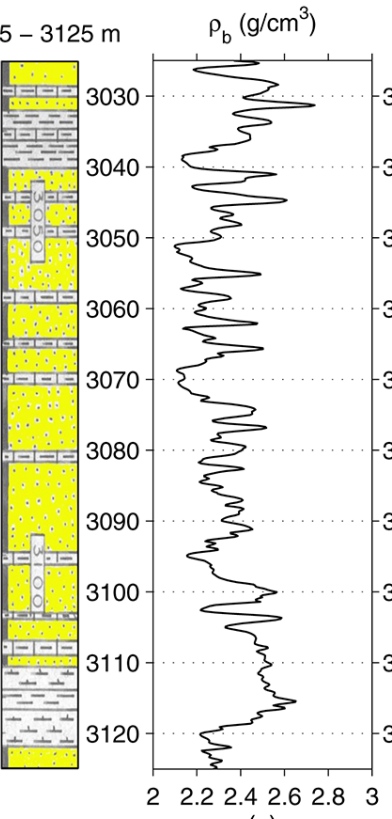

(c)

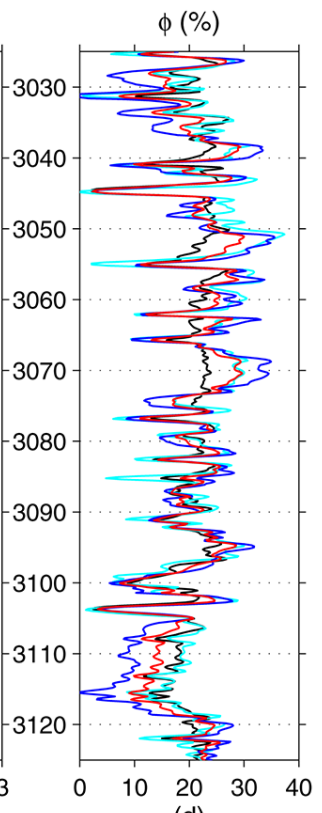

(d)

Figure 2 - Geophysical well-log data at the surroundings of WELL-A for the turbiditic sedimentary interval between 3025 and $3125 \mathrm{~m}$. Lithologies are depicted in the central panel, showing several oil-producing sandstone intervals intercalated by thin layers of calcareous shales, calcilutites, siltites, shales, and carbonates. The first panel in (a) exhibits the sonic slowness $\log (\Delta \mathrm{t}$, in $\mu \mathrm{s} / \mathrm{t}$ ) in blue color and the natural gamma-ray log (GR, in API units) in black color. The second panel in (b) shows the electrical resistivity log, i.e., induction logging deep (ILD, in Ohm.m). The density $\log \left(\rho_{\mathrm{b}}\right.$, in $\left.\mathrm{g} / \mathrm{cm}^{3}\right)$ is shown in panel (c). The last panel (d) presents the total porosity $\operatorname{logs}\left(\phi\right.$, in percent): the neutron porosity log, $\phi_{\mathrm{N}}$, in black color; the total density porosity log, $\phi_{\mathrm{t}, \mathrm{D}}$ as in Eq. (1), in blue color; the total sonic porosity log, $\phi_{\mathrm{t}, \mathrm{S}}$ as in Eq. (4), in cyan color; and the Gaymard porosity log, $\phi_{\mathrm{t}, \mathrm{ND}}$ as in Eq. (24), in red color. The parameters for total porosity calculations are given in the text.

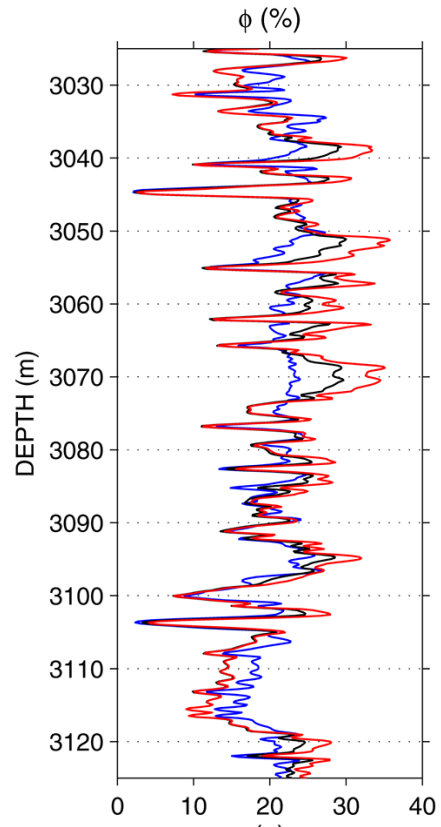

(a)

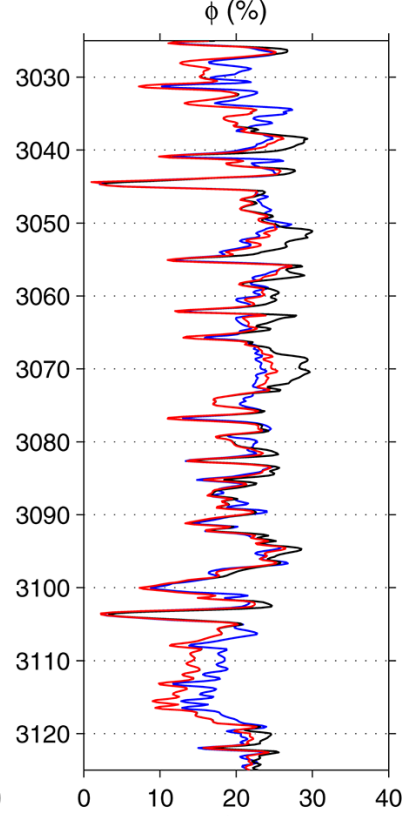

(b)

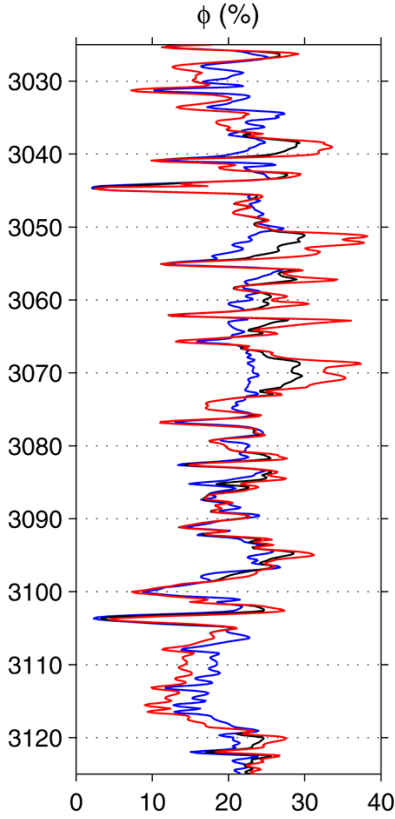

(c)

Figure 3 - Comparison of porosities (in \%) using the geophysical logs at the surroundings of WELL-A. The neutron porosity log, $\phi_{\mathrm{N}}$, is in blue color. The Gaymard porosity $\log , \phi_{\mathrm{t}, \mathrm{ND}}$ as in Eq. (24), is in black color. The approximated Gaymard porosity logs, $\phi_{\mathrm{t}, \mathrm{ND}}$, are in red color: in (a), the second-order approximation as in Eq. (A2); in (b), the third-order approximation as in Eq. (A3); and in (c), the fourth-order approximation as in Eq. (A4). 


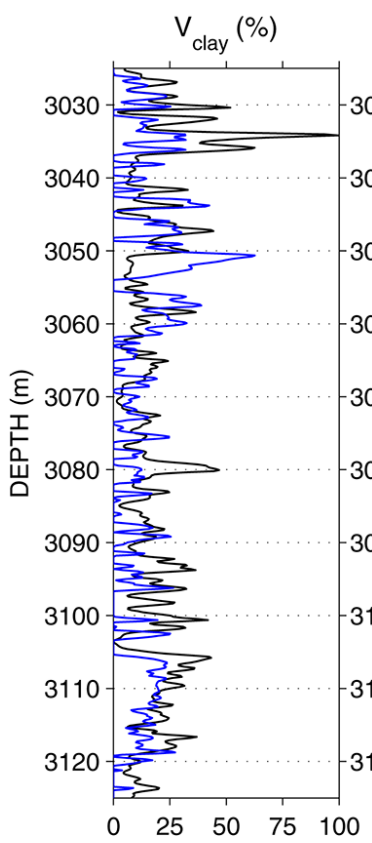

(a)

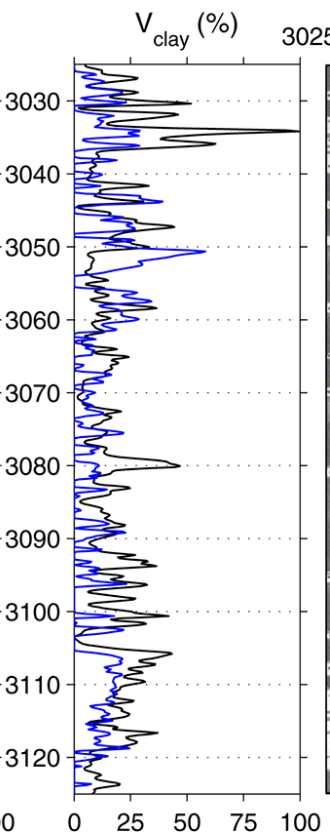

(b)

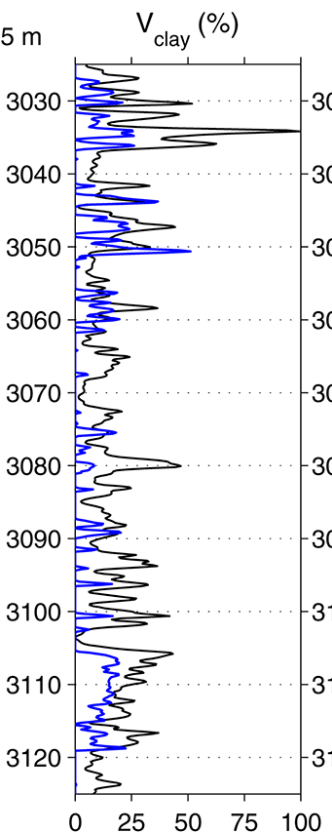

(c)

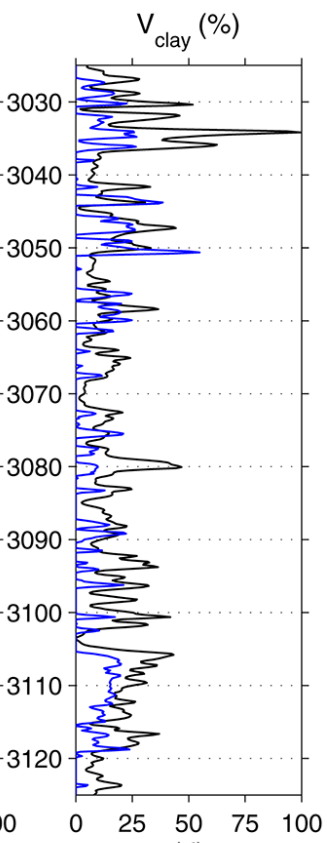

(d)

Figure 4 - Comparison of shaliness estimation in WELL-A using the empirical model proposed by Larionov (1969) - see Eq. (11) - with the petrophysical models described in the text. The Larionov (1969) model is in black color. The petrophysical models are in blue color: in (a), the Kamel \& Mabrouk (2003) model as in Eq. (21); and in (b), the Mabrouk \& Kamel (2011) as in Eq. (23). The new petrophysical models for shaliness derived by substituting the binomial approximation for Eq. (24): in (c), the model derived in Eq. (25), using the second-order binomial approximation in Eq. (A2); and in (d), the shaliness estimation with a petrophysical model similar to Eq. (25), but using the fourth-order binomial approximation given in Eq. (A4). As expected, the accuracy of shaliness estimation in Figure 4d has a slight increase in some depths in comparison to Figure 4c, because of the incorporation of high-order terms in the derivation of the petrophysical model. See in Table 2 the uncertainty analysis for shaliness estimation in WELL-A.

measurements of rock densities in Figure $5 \mathrm{c}$ and of sonic slownesses in Figure 5a were inserted into Eqs. (1), (4) and (24), respectively. The total porosity logs are plotted together with the neutron porosity $\log , \phi_{\mathrm{N}}$, in Figure $5 \mathrm{~d}$. As expected, the facies shown in the lithology column remain well marked in the porosity logs, while the Gaymard porosity log, $\phi_{\mathrm{t}, \mathrm{ND}}$, runs between the neutron porosity $\log , \phi_{\mathrm{N}}$, and the total density porosity $\log$, $\phi_{\mathrm{t}, \mathrm{D}}$.

Figure 6 depicts the total porosity logs which promote the comparison of the binomial approximations for Gaymard porosity using the geophysical data set from WELL-B. In the same way as verified with the measurements in WELL-A, the neutron porosity $\log , \phi_{\mathrm{N}}$, is displayed in the panels of Figure 6 as the reference porosity log. A gradual fitting of the second-, thirdand fourth-order binomial approximations with the exact Gaymard porosity $\log , \phi_{\mathrm{t}, \mathrm{ND}}$ as in Eq. (24), can be observed in Figures $6 \mathrm{a}, 6 \mathrm{~b}$ and $6 \mathrm{c}$, respectively. Although the third-order binomial approximation for Gaymard porosity shows a slightly better fitting, the overall behaviour of such approximations is very equivalent. Concerning the porosity logs using the data set from WELL-B, the uncertainty analysis in Table 1 corroborates the equivalence of the binomial approximations for Gaymard porosity.

In the same way, as with the data set in WELL-A, we used the geophysical measurements from WELL-B in order to compare the performance of the petrophysical models in the estimation of shaliness. As the reference for comparison, Larionov (1969) empirical model for young sediments clearly overestimates shaliness in the entire sedimentary interval, especially in the oilproducing, feldspar-rich sandstones. The incorporation of high gamma-ray amplitudes from the gamma-ray log measurements into Larionov (1969) empirical model leads to shaliness overestimation. Nevertheless, the petrophysical models proposed in Kamel \& Mabrouk (2003) and in Mabrouk \& Kamel (2011) provide more robust shaliness estimates - see Figure $6 a$ and $6 b$, respectively. Though exhibiting very slight differences, the estimates of shaliness using the new petrophysical models in Eqs. (25) and (27) that result from the binomial approximations of Gaymard porosity, provide an equivalent behaviour in the estimation of 


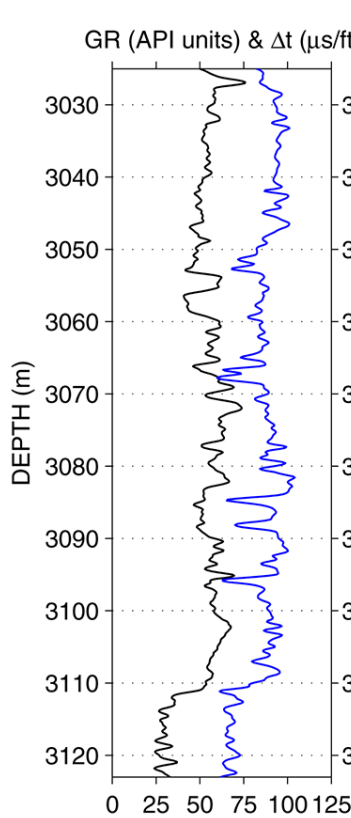

(a)

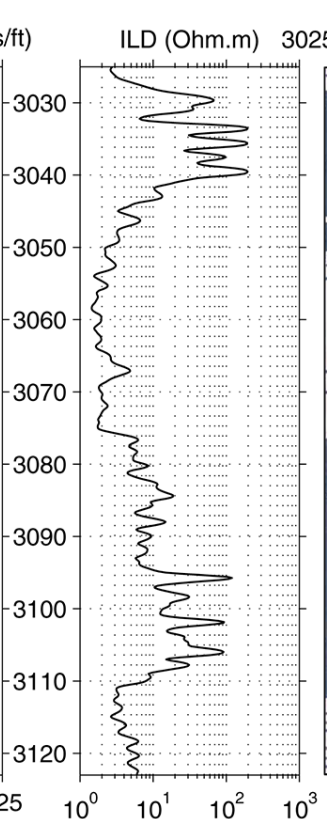

(b)

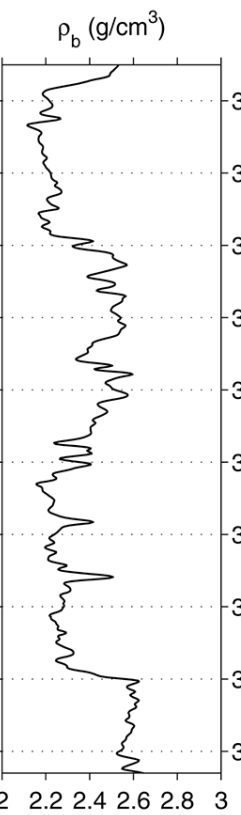

(c)

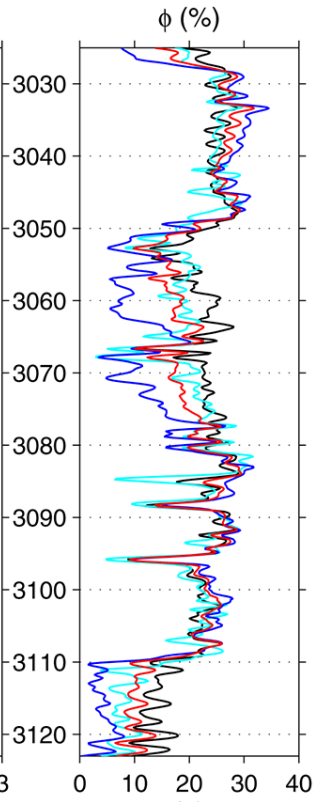

(d)

Figure $\mathbf{5}$ - Geophysical well-log data at the surroundings of WELL-B for the turbiditic sedimentary interval between 3025 and $3123 \mathrm{~m}$. The lithology column in the central panel shows two thick oil-producing shaly-sand zones. Shales and calcareous shales occur at the top and in the middle of the sedimentary interval, which is bounded by a carbonate at the bottom. The first panel in (a) exhibits the sonic slowness $\log (\Delta \mathrm{t}$, in $\mu \mathrm{s} / \mathrm{ft})$ in blue color and the natural gamma-ray log (GR, in API units) in black color. The second panel in (b) shows the electrical resistivity log, i.e., induction logging deep (ILD, in Ohm.m). The density $\log \left(\rho_{\mathrm{b}}\right.$, in $\left.\mathrm{g} / \mathrm{cm}^{3}\right)$ is shown in panel (c). The last panel (d) presents the total porosity logs ( $\phi$, in percent): the neutron porosity log, $\phi_{\mathrm{N}}$, in black color; the total density porosity log, $\phi_{\mathrm{t}, \mathrm{D}}$ as in Eq. (1), in blue color; the total sonic porosity log, $\phi_{\mathrm{t}, \mathrm{S}}$ as in Eq. (4), in cyan color; and the Gaymard porosity log, $\phi_{\mathrm{t}, \mathrm{ND}}$ as in Eq. (24), in red color. The parameters for total porosity calculations are the same as in Figure 2d.

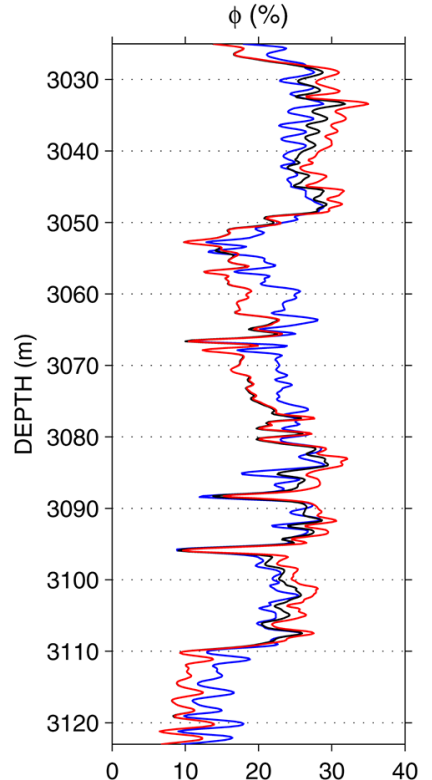

(a)

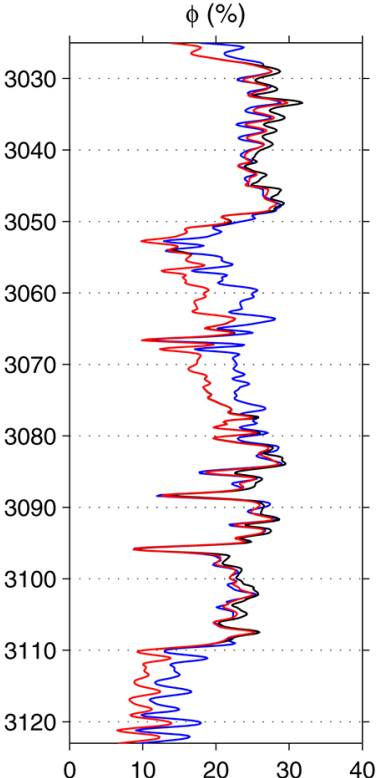

(b)

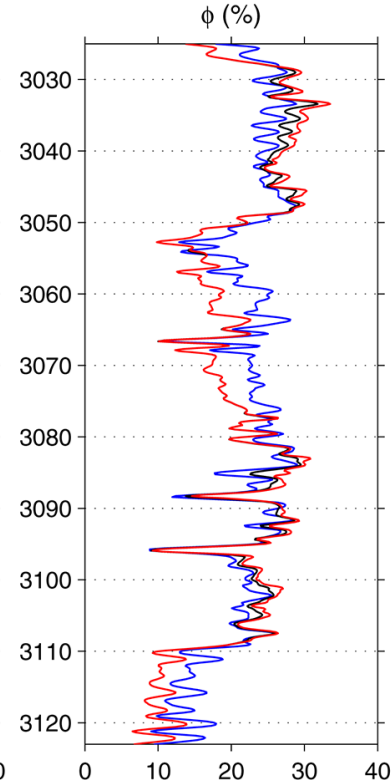

(c)

Figure 6 - Comparison of porosities (in \%) using the geophysical logs at the surroundings of WELL-B. The neutron porosity log, $\phi_{\mathrm{N}}$, is in blue color. The Gaymard porosity log, $\phi_{t, N D}$ as in Eq. (24), is in black color. The approximated Gaymard porosity logs, $\phi_{t, N D}$, are in red color: in (a), the second-order approximation as in Eq. (A2); in (b), the third-order approximation as in Eq. (A3); and in (c), the fourth-order approximation as in Eq. (A4). 
shaliness. In other words, shaliness estimation fundamentally dependents on porosity measurements rather than gamma-ray geophysical anomalies. The uncertainty analysis in Table 2 also points out the equivalence of the petrophysical models in estimating shaliness using the geophysical measurements from WELL-B.

\section{DISCUSSION AND CONCLUSIONS}

The above-derived new petrophysical models for estimating shaliness in clastic sedimentary rocks present similar properties as the previously proposed models in Kamel \& Mabrouk (2003) and in Mabrouk \& Kamel (2011). Following the same mathematical formulation of such works, we inserted the second-, the thirdand the fourth-order binomial approximations of the so-called Gaymard porosity formula into a simple shaliness-porosity relationship. As expected, the subsequent laborious algebraic manipulations provided robust new petrophysical models that are explicitly dependent on the measurements of basic porosity logs, that is, $\phi_{\mathrm{N}}, \Delta_{\mathrm{t}}$ and $\rho_{\mathrm{b}}$.

In the experiments using real well-log data sets from two vertical boreholes crossing a turbiditic oil-producing reservoir offshore Brazil, we focused on comparing the binomial approximations for Gaymard porosity formula and the estimations of shaliness using both the previously derived and the above-formulated new petrophysical models. The results of comparing the binomial approximations with the exact Gaymard porosity formula provided a very good fitting, which is corroborated by the uncertainty analyses described in Table 1. Indeed, these outcomes are the natural consequence of incorporating high-order terms into the approximations, gradually increasing accuracy. As for the shaliness estimations using the petrophysical models, the main finding from the experiments refers to the equivalent, less inaccurate and more realistic outcomes obtained, which are pointed out by the uncertainty analyses in Table 2. Although testing only the new petrophysical models derived with the second- and the fourth-order binomial approximations for Gaymard porosity formula, use of the petrophysical model formulated with the third-order approximation also would lead to an equivalent, less inaccurate and more realistic shaliness estimation. The secondary finding - which is indeed a confirmation of a previous result - is the shaliness overestimation provided by the empirical model taken as reference for the sedimentary rocks studied.

The petrophysical models here investigated also exhibit crucial dependence on a priori information handled along conventional well-log interpretation workflows, that is, the parameters $\Delta \mathrm{t}_{\mathrm{ma}}, \Delta \mathrm{t}_{\mathrm{f}}, \Delta \mathrm{t}_{\text {clay }}, \rho_{\mathrm{ma}}, \rho_{\mathrm{f}}$ and $\rho_{\text {clay }}$. Special attention must be drawn to selecting the parameters at the "shale point", i.e., $\Delta \mathrm{t}_{\text {clay }}$ and $\rho_{\text {clay }}$, since poorly selected values for such parameters can lead to unrealistic shaliness estimations. Moreover, the property of depending only on the readings of basic porosity logs rather than on the gamma-ray intensities provides robustness to the petrophysical models for shaliness. In this way, estimates of shaliness are free from contamination of gamma-ray anomalies in intervals containing highly-radioactive minerals - feldspars, for instance. As a result, the more realistic estimates of shaliness obtained with the pretrophysical models represent a guarantee of estimating oil reserves with less uncertainty.

Finally, note that assuming Eq. (8) in the mathematical formulations has provided special cases of petrophysical models for shaliness estimation - that is, take $\delta=0.5$ in Eq. (7) to obtain Eq. (8). Using the same formulation as above, more general new petrophysical models for shaliness estimation can be obtained with Eq. (7). However, the resulting petrophysical models will clearly depend on the additional parameter $\delta$. As it corresponds to an empirical parameter, the selection of $\delta$ requires a cautious priori investigation in order to avoid leading to unrealistic shaliness estimates.

\section{ACKNOWLEDGMENTS}

The PIBIC-ON/CNPq-MCTI supported Thais Mallet de Castro (process no. 115.307/2013-3). Preliminary results of this paper were presented at the "Jornada de Iniciação Científica do Observatório Nacional 2016, Rio de Janeiro, Brazil", and at the "VII Simpósio Brasileiro de Geofísica 2016, Ouro Preto, Brazil".

\section{A APPENDIX}

This appendix shows the binomial approximation for the Gaymard porosity formula (Gaymard \& Poupon, 1970) in Eq. (9). In order to verify the accuracy of the approximation - see Figures 3 and 6 - we present in the following the second-, the third- and the fourth-order approximations for $\phi_{\mathrm{t}, \mathrm{ND}}$, that are needed in the mathematical formulation of the new petrophysical models for shaliness in Eqs. (25) and (27).

The binomial formula can be formally expressed up to the fourth term as (Boas, 1983),

$$
\begin{aligned}
(a+ & b)^{n}=a^{n}+n a^{n-1} b+\frac{n(n-1)}{2 !} a^{n-2} b^{2} \\
& +\frac{n(n-1)(n-2)}{3 !} a^{n-3} b^{3} \\
& +\frac{n(n-1)(n-2)(n-3)}{4 !} a^{n-4} b^{4}+\ldots
\end{aligned}
$$

where $n$ is any real, positive or negative number. The objective 


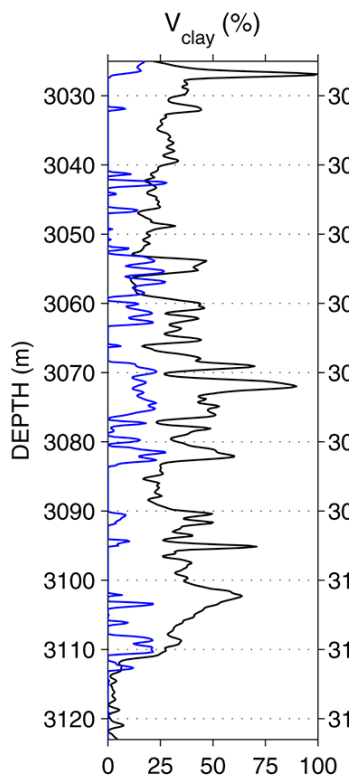

(a)

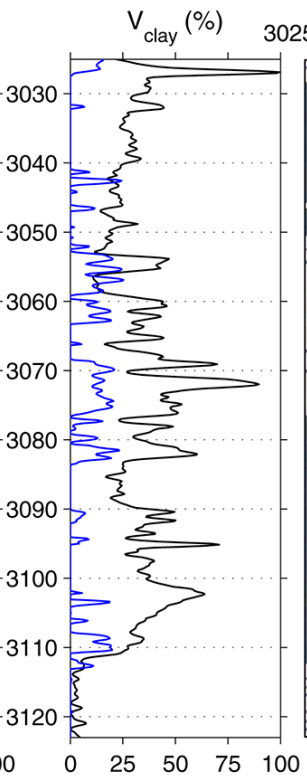

(b)

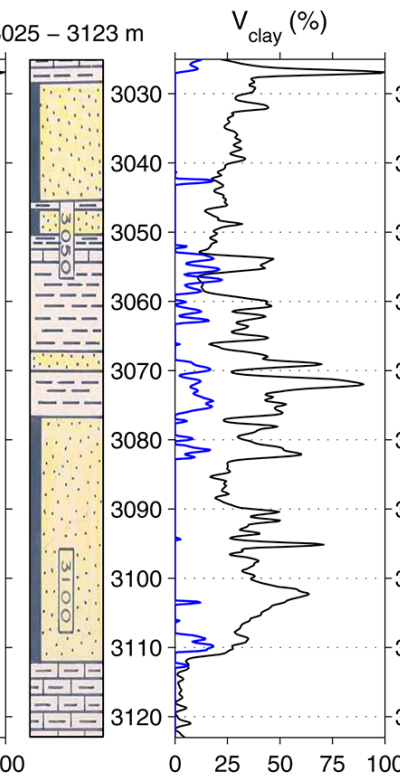

(c)

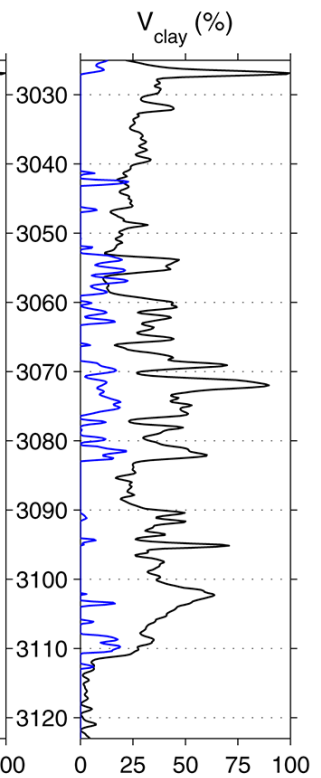

(d)

Figure 7 - Comparison of shaliness estimation in WELL-B using the empirical model proposed by Larionov (1969) - see Eq. (11), with the petrophysical models described in the text. The Larionov (1969) model is in black color. The petrophysical models are in blue color: in (a), the Kamel \& Mabrouk (2003) model as in Eq. (21); and in (b), the Mabrouk \& Kamel (2011) as in Eq. (23). The new petrophysical models for shaliness derived by substituting the binomial approximation for Eq. (24): in (c), the model derived in Eq. (25), using the second-order binomial approximation in Eq. (A2); and in (d), the shaliness estimation with a petrophysical model similar to Eq. (25), but using the fourth-order binomial approximation given in Eq. (A4). Comparing with Figure 7c, the accuracy of shaliness estimation in Figure 7d slightly increases in some depths, because of the incorporation of higher-order terms in the derivation of the petrophysical model. See in Table 2 the uncertainty analysis for shaliness estimation in WELL-B.

here is to approximate the Gaymard porosity in Eq. (24) using the binomial formula. To this end, we then substitute $n=1 / 2$, $a \equiv \phi_{\mathrm{N}}^{2}$ and $b \equiv \phi_{\mathrm{t}, \mathrm{D}}^{2}$. As a result, using Eq. (A1), the secondorder approximation for $\phi_{\mathrm{t}, \mathrm{ND}}$ can be written as:

$$
\phi_{\mathrm{t}, \mathrm{ND}} \approx \sqrt{\frac{1}{2}}\left(\phi_{\mathrm{N}}+\frac{\phi_{\mathrm{t}, \mathrm{D}}^{2}}{2 \phi_{\mathrm{N}}}\right)
$$

Note the misprint of Eq. (A2) in Castro \& Martins (2016).

In the same way, the third-order binomial approximation for Eq. (24) is given as

$$
\phi_{\mathrm{t}, \mathrm{ND}} \approx \sqrt{\frac{1}{2}}\left(\phi_{\mathrm{N}}+\frac{\phi_{\mathrm{t}, \mathrm{D}}^{2}}{2 \phi_{\mathrm{N}}}-\frac{\phi_{\mathrm{t}, \mathrm{D}}^{4}}{8 \phi_{\mathrm{N}}^{3}}\right)
$$

and the fourth-order binomial approximation as,

$$
\phi_{\mathrm{t}, \mathrm{ND}} \approx \sqrt{\frac{1}{2}}\left(\phi_{\mathrm{N}}+\frac{\phi_{\mathrm{t}, \mathrm{D}}^{2}}{2 \phi_{\mathrm{N}}}-\frac{\phi_{\mathrm{t}, \mathrm{D}}^{4}}{8 \phi_{\mathrm{N}}^{3}}+\frac{\phi_{\mathrm{t}, \mathrm{D}}^{6}}{16 \phi_{\mathrm{N}}^{5}}\right) .
$$

Figures 3 and 6 show the accuracy in calculating the total neutrondensity porosity $\phi_{t, \mathrm{ND}}-$ i.e., the Gaymard porosity in Eq. (24), using the binomial approximations in Eqs. (A2), (A3) and (A4).

\section{REFERENCES}

ASQUITH G \& GIBSON C. 1983. Basic well log analysis for geologists. AAPG Methods in Exploration Series, no. 3, 216 pp.

BACOCCOLI G, MORALES RG \& CAMPOS 0J. 1980. The Namorado oil field: A major discovery in the Campos basin, Brazil. AAPG Bulletin, 63: 329-338.

BOAS ML. 1983. Mathematical methods in the physical sciences. 2nd ed., New York, NY: John Wiley \& Sons, 793 pp.

BROCK J. 1984. Analysing your logs: Advanced Open Hole Log Interpretation. Petromedia, vol. 2: $173 \mathrm{pp}$.

CASTRO TM \& MARTINS JM. 2016. Modelo petrofísico para estimativa da argilosidade: uma nova formulação. In: Anais do VII Simpósio Brasileiro de Geofísica, 25-27 outubro, Ouro Preto, MG, Brazil, CD-ROM (In Portuguese).

CASTRO TM, MARTINS JM, MOREIRA TAD, SANTOS MAC \& ARAÚJO JF. 2014. Argilosidade em sedimentos clásticos: modelos empíricos $\times$ modelos petrofísicos. In: Anais do VI Simpósio Brasileiro de Geofísica, 14-16 de outubro, Porto Alegre, RS, Brazil, CD-ROM (/n Portuguese).

CLAVIER C, HOYLEWR \& MEUNIER D. 1971. Quantitative interpretation of TDT logs: Parts I and II. J. Pet. Technol., 23: 743-763. 
DEWAN JT. 1983. Essentials of modern open-hole log interpretation. Tulsa, OK: PennWell Publishing Co., 361 pp.

ELLIS DV \& SINGER JM. 2007. Well logging for Earth scientists. 2nd ed., Dordrecht, The Netherlands: Springer, 692 pp.

GAYMARD RD \& POUPON A. 1970. The evaluation of clay content from logs. In: Trans. of SPWLA 11th Annual Logging Symposium, 3-6 May, Los Angeles, California, 1-21.

KAMEL MH \& MABROUK WM. 2003. Estimation of shale volume using a combination of the three porosity logs. Journal of Petroleum Science and Engineering, 40: 145-157.

LARIONOV WW. 1969. Borehole radiometry. Moscow: Nedra, 127 pp. (In Russian).

MABROUK WM \& KAMEL MH. 2011. Shale volume determination using sonic, density and neutron data. Exploration Geophysics, 42: 155-158.

MAGALHÃES MF \& MARTINS JL. 2012. Petrophysical model for bulk density of complex lithologies. Brazilian Journal of Geophysics, 30(1):
$63-79$.

PENNINGTON WD. 2000. Reservoir Geophysics. Geophysics, 66: 2530.

SCHÖN JH. 1996. Physical Properties of Rocks: Fundamentals and principles of petrophysics. London: Pergamon, 583 pp.

STIEBER SJ. 1970. Pulsed neutron capture log evaluation - Louisiana Gulf Coast. In: Society of Petroleum Engineers Annual Fall Meeting Proceedings, SPE 2961, Houston, TX, p. 4-7.

TIGRE CA \& LUCCHESI CF. 1986. Estado atual do desenvolvimento da Bacia de Campos e perspectivas. In: Seminário de Geologia de Desenvolvimento e Reservatório, DEPEX-PETROBRAS, Rio de Janeiro, Brazil, 1-12 (In Portuguese).

WYLLIE MRJ, GREGORY AR \& GARDNER GHF. 1958. An experimental investigation of factors affecting elastic wave velocities in porous media. Geophysics, 23: 459-493. 